\title{
The University-Industry-Government Triple Helix innovation model with innovation and entrepreneurship base as the node
}

\author{
_ Based on the perspective of interactive development between urban university and \\ regional industry \\ Dan Liu ${ }^{1, ~ a}$, Xiaoyue Liu' ${ }^{2, b}$, Wang Luo ${ }^{3, *}$ \\ ${ }^{1}$ Business School, Jianghan University \\ ${ }^{2}$ The University of Queensland Business School Business, Economics \& Law Postgraduate \\ ${ }^{3}$ Institute of Agricultural economy and Technology, Hubei Academy of Agricultural Sciences \\ a136782581@qq.com, ${ }^{\mathrm{b}}$ xiaoyue.liu.jenny@gmail.com. \\ *corresponding author
}

Keywords: Triple Helix, innovation model, innovation and entrepreneurship base.

\begin{abstract}
Since professor Etzkowitz, an American scholar, and professor Leydesdorff, a Dutch scholar, proposed the theory of "university-industry-government" Triple Helix cooperative innovation system, the positive role of "university- industry- government " cooperation and interaction in promoting regional economic development has been widely recognized. However, in China, the research on how the "university-industry-government" Triple Helix cooperative innovation system promotes regional economic and social development is limited to the theoretical elaboration of " function ", "relationship" and "influencing factors", while the exploration on the practical aspect is short of substance and operability. From the perspective of the development of China's real economy, the development strategy of supply-side reform urgently needs innovation and entrepreneurship to change the traditional economic structure, so the "university-government-industry" cooperative innovation mechanism with great breakthroughs is more needed. Based on the interpretation of the Triple Helix innovation model and the research on the establishment practice of various university science and technology parks, this study will discuss how to build the regional triple helix innovation system with the innovation and entrepreneurship base of wuhan local university as the node, as well as related policy Suggestions.
\end{abstract}

\section{Triple Helix innovation theory and model}

A basic idea of the "university-industry-government" cooperative innovation model is to promote regional innovation activities by giving play to their respective resource advantages and capabilities. In professor Etzkowitz triple helix innovation model, university and industry, the government, the three groups in addition to traditional functions performed in the interaction between organizations also derived a series of new functions, such as the university in addition to exert the function of education and to carry out the basic research, can also play the role of enterprise, to use their own research and development to form a new company, or in the process of technical transformation to the product to participate in the activities of the development of the enterprise; The government can also support and guide the innovative research and entrepreneurship activities of the research institutes and the cooperative innovation of the research institutes and enterprises by funding projects and improving the operating environment. While performing the social management function, the government also plays the role of product purchase, venture investment and financial services in part. Under certain conditions, enterprises can also play the role of universities, such as carrying out training and development research with the same high level as universities ${ }^{[1]}$.In the Triple Helix system, each of the three main bodies has its own core area and the external field area interacting with other mechanisms. The part where they jointly participate and integrate with each other -- the interaction external field area -- constitutes a cooperative 
alliance of "university-industry-government", and drives the dynamic upward spiral of regional innovation activities through feedback and radiation ${ }^{[2] .}$

At present, the typical successful model is :(1) university-led model -- represented by the Stanford science park in the United States, which is known as the "silicon valley model";(2) Corporate-pushed model -- with Cambridge science park as the typical representative. The biggest characteristic of Cambridge science park is that it attracts some powerful private enterprises to invest, operate and manage the university science park construction because the government supports Cambridge university with obvious advantages in knowledge accumulation, invention patents and scientific research talents in policies, funds and systems.(3) government-pulled model. Japanese tsukuba science city is a typical "government-oriented" science park, whose formation and development are entirely subject to the administrative decisions of the government. In the development process of science and technology parks, the government's capital investment occupies a dominant position. For more than 30 years, the city has received a total of 2.5 trillion yen in government investment. About $40 \%$ of the national scientific research institutions and $40 \%$ of the annual scientific research budget are concentrated here, representing the most advanced scientific research and development level in Japan ${ }^{[3]}$.

\section{Practical significance and feasibility}

After more than 30 years of traditional development driven by factors and investment, China's economy is facing a new growth stage of development transition and power transformation. In this new phase of growth, we will grow from a learner into a leader, The free ride we used to take has no place in our future, everything will depend on our own innovation. From the perspective of regional development and social leadership, it is the most effective choice to build a "universityindustry- government" cooperative innovation platform.

First of all, in the era of knowledge economy, due to the rising status of academic and research institutions, universities have become the three leading institutions for regional economic and social development with the government and industry. As a result, innovative collaboration at this level will be more likely to achieve regional and strategic objectives. Moreover, the differences and complementarities among the three in their respective resources and functions also become an important basis for their cooperation.

Secondly, different from the cooperation mode of "production- university -research", which is based on specific projects, the Triple Helix cooperation innovation mode of "university- industrygovernment" aims to establish a sustainable regional innovation system. It is particularly important in the innovation-driven development strategy advocated by the country today, to promote the sustainable development of regional innovation activities taking the hybrid organization formed by the "university-industry-government" cooperative innovation mechanism as the source of the storm.

Thirdly, innovation is to realize a "new combination" of production factors or conditions. As a high-level organizational model, the "university-industry-government" Triple Helix cooperation mechanism is more convenient to carry out "new combination" of production factors or production conditions within the region, thus leading and supporting regional innovation activities.

For the cooperation between urban and local universities and governments and industries concerned in this paper, a prominent problem is the "critical mass" effect. So far, effective Triple Helix collaborative innovation networks have mostly relied on top or domain-influential universities. Therefore, it is often doubted that city and local universities can successfully build a Triple Helix cooperative innovation system with local government and industry. However, the laws of today's Internet have proven that "centrism" has no future. A complete innovation system should be composed of multiple levels. Just like the countless "nodes" of the Internet, the cooperative alliance formed by the combination of urban and local universities, local governments and industries has its own value and mission, which also needs to be accomplished through innovation.

From the perspective of mutual interests, the establishment and operation of China's urban and local universities are funded by the financial support of the local government. This makes local governments more motivated to support the role of city universities in the triple helix collaborative 
innovation system and achieving growth from it. These support includes not only policies, funds, personnel, land, but more importantly government procurement from local projects. For example, the planning and construction of the national university science and technology park of Shanghai university has been supported by a number of industrial projects and funds including "multimedia software development and multimedia display technology", "nanotechnology" and "automobile industry city" in Shanghai.

It should be noted that although the theory and model of the Triple Helix have universal guiding significance, from the current situation, China still has practical problems that must be overcome in the relevant exploration:

First, the outstanding problem is that the university is not ready for the third mission. The emphasis on academics over technology and on professional titles over practice makes universities less connected to local economic and social development, and knowledge products lose the opportunity to realize their value. At the same time, the funds needed for its own development depend only on a single source of government finance.

Secondly, some local governments lack the strategies and means to effectively participate in and support the development of the Triple Helix innovation network, and lack the system construction in policies and regulations, thus greatly reducing their main role in regional innovation activities. This state outside the innovation system not only leads to the waste of a lot of resources and the loss of opportunities, but also increases the institutional cost of inaction.

Third, insufficient investment in R\&D, whether by companies, universities or governments, has left regional innovation severely "anemic". At the same time, due to the lack of forward-looking risk, benefit allocation mechanism design, the capital input channels of R\&D activities are not smooth.

Fourth, there is a lack of innovative "engine" enterprises ${ }^{[3][4]}$, which makes the whole society's innovation activities lack of continuous guidance and promotion. At the same time, the innovation biological chain also lacks the orderliness power.

\section{Policy recommendations}

The construction of the "university-industry-government " Triple Helix cooperative innovation network cannot be achieved by subjective will, In view of the aforementioned problems existing in the cooperative innovation exploration of "university-industry-government " in China and combined with the experience of the first batch of national "mass entrepreneurship and innovation" demonstration bases, We put forward the following Suggestions on how to build a regional "university-industry-government” Triple Helix cooperative innovation network under the guideline of "mass entrepreneurship and innovation":

\subsection{The choice of cooperation carrier}

The actual operation of the Triple Helix cooperative innovation mode needs to select the appropriate carrier, combined with the State Council's plan to build a base of " Mass entrepreneurship and innovation ", It is a favorable choice to construct the "UniversityIndustry-Government " Triple Helix cooperative innovation alliance and network node based on mass entrepreneurship and innovation base of local city university. Within the base, diversified systems such as business incubator, crowd innovation space, university derivative company and public laboratory can also be built through garden in garden.

\subsection{The choice of collaborative innovation mode}

According to the characteristics of our country's existing economic system and the reality of the local city universities' own R \& D and technological transformation ability, we suggest choosing the government-oriented model to construct the early alliance system of "university-industry-government" Triple Helix cooperation and innovation. In fact, the status of the three parties in the Triple Helix cooperation mode is dynamic, which depends on their abilities and their respective growth and maturity characteristics in different development periods of the Triple 
Helix system. As the cooperative alliance matures, universities or industries may become the leading and organizers of the innovation community.

\subsection{Give full play to the leading role of the government in the initial stage of innovation alliance}

First, improve the policy system, and provide legal, policy and economic guarantee for the construction of "double innovation" base, science and technology park, tripartite cooperation and innovation activities. The second is to change the way of investment in university scientific research funds, and use project procurement to partly replace fund allocation. Guide and support local universities to participate in local economic and social development. The third is to establish a public venture capital fund which is different from and complementary to the commercial venture investment style and has long-term stability, so that the Triple Helix innovation alliance can get the independent fund source with legal guarantee.

\subsection{The transformation of university subject}

Modern university is not only the cradle of talent cultivation, but also the laboratory of scientific research, especially basic research, and the birthplace of major scientific and technological achievements. Whatever its initial role in the innovation alliance, it will eventually become the source and propeller of innovation. Based on this, with the evolution and development of the Triple Helix cooperative innovation system, the university will move forward from the rear and become an innovative university. Therefore, local city universities should actively explore knowledge capitalization, openness, and innovative management ability to realize the transformation of the model of university -running.

\subsection{Attract and breed "engine" enterprises}

The experience of developed countries has proved that "engine" enterprises are the core of the innovation network, and the formation of "engine" enterprises is based on the existence of a large number of small and medium-sized enterprises and stands out in technological change. We can't predict its occurrence, but we can create the soil and environment that are easy for it to occur and grow. Include: Carry out system innovation in local experimental area; To build a market space suitable for the survival, competition and development of small and micro enterprises; Active develop human resource services, technology transfer services, financial capital services, management information consulting services, financial services and legal services, to construct the industrial ecology conducive to the survival and development of innovative enterprises; Create cultural atmosphere and social fault-tolerant mechanism that encourages innovation and tolerates failure. Let innovative enterprises grow into innovative "engine" enterprises through policy encouragement, legal guarantee, venture capital support and market screening.

\subsection{Guiding synchronization}

Synchronization is an important condition for the smooth transfer of the regional Triple Helix innovation system in the knowledge space, resource space and target space, and also a key factor to determine the performance of the Triple Helix innovation cooperation system. This requires research institutes, industry and government to reach consensus through repeated discussion, design and verification. It will be the most feasible and direct scheme for the government to guide such "synchronization" through the implementation of regional development strategies and projects, as well as the advantageous technology development guidelines and government public product orders ${ }^{[5]}$.It is possible to communicate concerns, integrate resources and coordinate actions by forming a decision-making committee with the participation of representatives from universities, industries and governments.

\section{References}

[1] Zhou chunyan. University - industry - government Triple Helix innovation model -- review and 
introduction of Henry Etskovitz's “Triple Helix "[J]. Research on natural dialectics, 2006(4):75-77.

[2] Etzkowitz H, Leydesdorff L. The dynamics of innovation: From national systems and 'Mode 2'to a Triple Helix of university-ndustry-government relations [J]. Research Policy, 2000, 29(2):109-123

[3] Zhao dongxia, guo shunan, zhou wei. Comparative study of collaborative innovation model in science and technology parks of foreign universities-from the perspective of the Triple Helix theory [J]. Chinese higher education research, 2016(11):89-93.

[4] Hu shaohong, huang li, du debin. The practice of building a global center for technological innovation - an analysis based on the tri-helix and innovation ecosystem perspective - takes Silicon Valley as an example [J]. Shanghai economic research.2016 (3):21-28.

[5] Etzkowitz H. The Triple Helix: University-Industry-Government Innovation in Action [M]. New York: Routledge, 2008 